\title{
Dostosowanie robotów do spawania elementów o obniżonej dokładności
}

\author{
Adaptation of welding robots control systems \\ to joining parts of lower dimensional accuracy
}

\section{Streszczenie}

Spawanie zrobotyzowane elementów o obniżonej dokładności lub niedokładnie pozycjonowanych jest jednym z ważniejszych wyzwań stojących przed projektantami wdrażanych stanowisk. Dobór skutecznej metody korekcji kształtu lub położenia części nie musi zawsze oznaczać radykalnego wzrostu kosztów inwestycyjnych i stopnia skomplikowania stanowiska.

W artykule omówiono najważniejsze, z punktu widzenia powszechności stosowania, metody korekcji kształtu i położenia spawanych elementów oraz koncepcję autorskiego opracowania, będącego przedmiotem prac wdrożeniowych.

\section{Wstęp}

Roboty przemysłowe są jednym z najważniejszych środków do elastycznej automatyzacji dyskretnych procesów produkcyjnych. Dzięki łatwości programowania i przystosowania do nowych zadań, znajdują zastosowanie zarówno przy produkcji wielkoseryjnej, jak i jednostkowej. Sukces, a więc wykorzystanie przewagi robota nad człowiekiem, możliwy jest tylko wtedy, gdy ograniczenia maszyny nie stanowią przeszkody $w$ realizacji zadania. Jednak pomimo wieloletniego rozwoju, nadal funkcjonuje wiele mitów związanych

Dr inż. Paweł Cegielski, dr hab. inż. Andrzej Kolasa prof. nzw. PW- Politechnika Warszawska, dr inż. Tadeusz Sarnowski - ZAP Robotyka, Ostrów Wielkopolski.

\section{Abstract}

Automatic welding of parts of lower dimensional accuracy preparation with the use of industrial robots is one of an important challenge for robotic installation designers as well as manufacturing engineers. The best method of the workpieces position correction to be choose for a particular application not always has to cause the increase in cost investment or the robotic system complication. Some of most widely used methods of the work position correction with the use of robot control software and hardware are described in this paper. A concept of authors proposal of such a method to be soon implemented to industrial practice is also presented. z nadzwyczajnymi możliwościami robotów. Jednym z nich jest przekonanie, że powtarzalność wymiarowa spawanych elementów nie jest istotna. W praktyce wiele procesów technologicznych, w tym spawalniczych, realizowanych jest przy wykorzystaniu robotów pozbawionych jakichkolwiek układów sensorycznych, a więc niezdolnych do samoczynnego dostosowania do zmieniających się warunków zewnętrznych.

Istnieje wiele powodów utrudniających lub uniemożliwiających uzyskanie niezbędnej powtarzalności wymiarowej części przeznaczonych do spawania, w tym:

- brak możliwości technicznych wytwórcy, w tym maszyn i procesów produkcyjnych,

- niskie wymagania wymiarowe w stosunku do wyrobu końcowego, nieuzasadniające wysokiej dokładności elementów składowych,

- trudności z dokładnym mocowaniem i pozycjonowaniem części spawanych ze względu na ich złożony kształt, dużą liczbę elementów składowych, znaczną masę czy wymiary, 
- zmiana wymiarów i/lub położenia części pod wpływem realizowanego procesu technologicznego, np. na skutek odkształceń spawalniczych wynikających z naprężeń cieplnych.

\section{Sensory wbudowane}

Wśród środków zaradczych dostępne są wbudowane do wielu systemów sterowania robotów programowe metody korekcji położenia i kształtu spawanych elementów. Ich działanie przeważnie wymaga użycia specjalnie przystosowanych źródeł spawalniczych, związanych z układem sterowania robota połączeniem sieciowym, np. DeviceNet.

Najprostsze metody oparte zostały na detekcji dotykowej narzędziem (końcem drutu elektrodowego lub dyszą gazową dla głowic MIG/MAG) położenia ele-

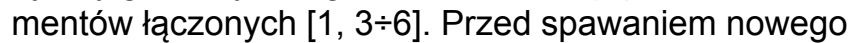
zespołu robot wykonuje zaprogramowane ruchy pomiarowe, a po porównaniu pozycji zaprogramowanej z rzeczywistą i dokonaniu niezbędnych przeliczeń przystępuje do spawania według skorygowanej, przesuniętej i/lub obróconej trajektorii (rys. 1a). Nowoczesne roboty mogą być wyposażone w biblioteki schematów „poszukiwania”, różniących się kształtem oraz rodzajem odchylenia. Niektóre systemy oferują dodatkową funkcjonalność, jak ustawianie stałej długości wolnego wylotu drutu elektrodowego czy potwierdzanie obecności detali (rys. 1b i 1c) [3]. Największymi zaletami metod dotykowych jest niski koszt oraz łatwość zastosowania (rys. 2). Wśród ograniczeń zwraca uwagę stosunkowo wolne działanie (pomiar poprzedzający spawanie), korekta ograniczona tylko do kilku charakterystycznych punktów i nieuwzględniająca zależności pomiędzy nimi, brak reakcji na ewentualne odkształcenia spawalnicze, czy też brak możliwości detekcji obszarów o bardzo małych rozmiarach, np. większości rowków spawalniczych.

W zależności od jakości spoiny, możliwe jest zastosowanie ciągłej korekty trajektorii robota podczas spawania, opartej na precyzyjnej analizie parametrów

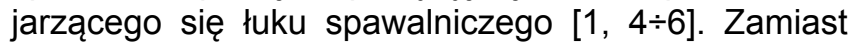
wcześniej zaprogramowanej, często zgrubnej, realizowana jest trajektoria odpowiadająca rzeczywistemu a)

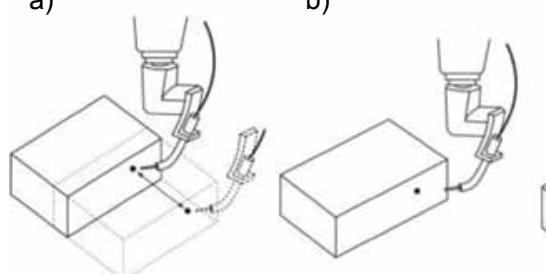

c)

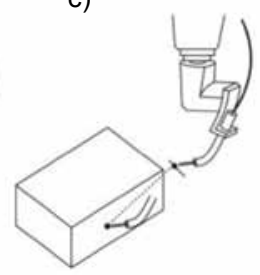

Rys. 1. Zasada działania detekcji dotykowej stosowanej w robotach przemysłowych do: a) kompensacji pozycjonowania elementu, b) ustawiania stałej długości wolnego wylotu drutu elektrodowego, c) potwierdzania obecności detalu [3]

Fig. 1. The principle of the touch detection method employed in industrial robots for: a) work positioning compensation, b) electrode wire extension adjustment, c) work present detection [3]

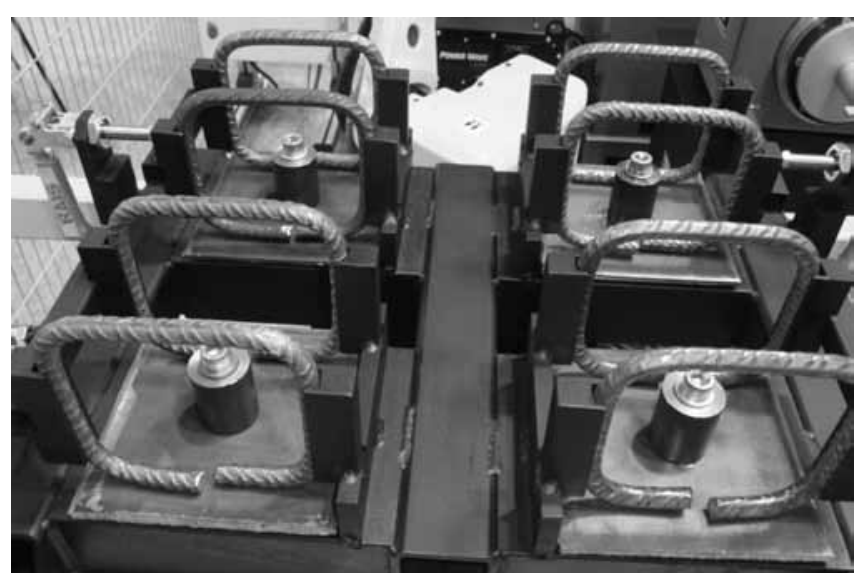

Rys. 2. Przykład części o bardzo małej powtarzalności wymiarowej, wymagających zastosowania funkcji detekcji dotykowej do każdej korekty położenia spoin łączących zaczepy z podstawą

Fig. 2. An example of lower dimensional accuracy parts to be welded with the use of the touch detection for each weld accomplishment

przebiegowi całej spoiny, a ewentualne odchylenia przebiegu spawanego rowka pod wpływem procesu są na bieżąco korygowane. Istotą korekty jest detekcja zmian prądu spawania powstających w czasie układania ściegów zakosowych. Jest to zarazem największe ograniczenie metody, uniemożliwiające jej stosowanie w przypadku połączeń cienkościennych, albo złączach doczołowych bez wyraźnie zaznaczonego rowka spoiny. Istnieje również wiele problemów technologicznych związanych z doborem parametrów spawania gwarantujących skuteczne działanie funkcji korekcyjnych.

\section{Laserowe czujniki triangulacyjne}

Alternatywą dla funkcji wbudowanych mogą być zewnętrzne sensory oparte na triangulacji laserowej $[2,7]$. W odróżnieniu od systemów punktowych (jednowymiarowych - 1D) z projekcją pojedynczej plamki laserowej na mierzoną powierzchnię, nowoczesne czujniki pozwalają na pomiar odległości czujnika dla zdefiniowanej linii (2D). Projekcja linii laserowej nie wymaga obecnie ruchomych części czujnika, a detektory CMOS umożliwiają bardzo szybki i dokładny pomiar.

Projekcja linii pomiarowej prostopadle do kierunku spawania umożliwia ocenę zaburzeń w dwóch kierunkach - poprzecznym oraz wysokości, obrazujących przekrój rowka, przesunięcie łączonych krawędzi itp. Uzyskana dwuosiowa korekta położenia osi elektrody, jej wysokości i przesunięcia poprzecznego, uzupełniona zostaje o trzecią oś - ruch czujnika wzdłuż skanowanej powierzchni, dając ostatecznie system analizy 3D (rys. 3).

Dzięki wysokiej rozdzielczości pomiarowej otrzymuje się precyzyjne narzędzie do detekcji nawet niewielkich odchyłek od pierwotnego położenia elementów, obrabianych krawędzi, w tym rowków spoin itp. Możliwe jest rozpoznawanie szczelin o szerokości 


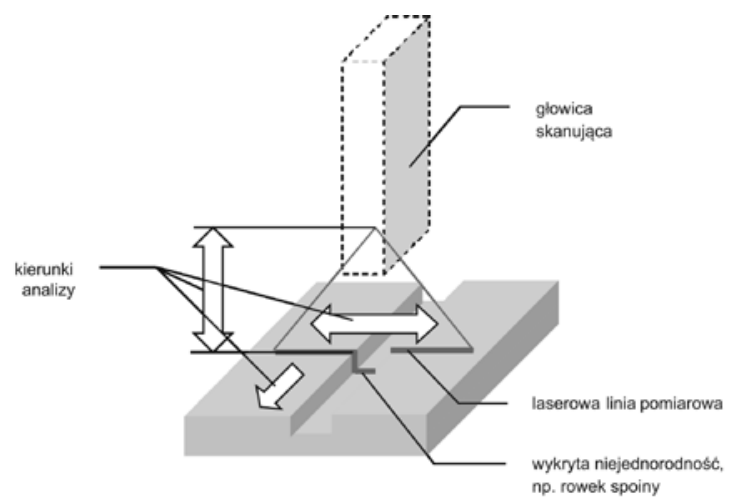

Rys. 3. Idea śledzenia rowka spoiny za pomocą triangulacyjnego czujnika liniowego

Fig. 3. The general idea of welding groove observation with the use of the triangular laser line sensor
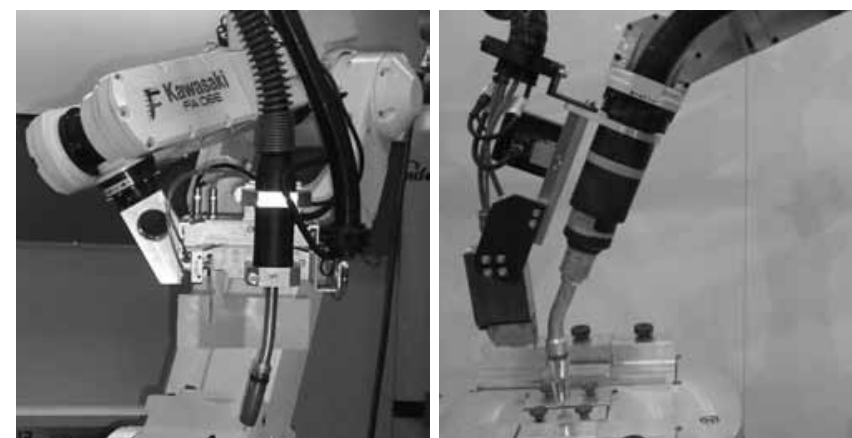

Rys. 4. Głowice spawalnicze $z$ laserowym czujnikiem triangulacyjnym (Kawasaki, Fanuc).

Fig. 4. The example of robot welding heads with triangular laser sensors (Kawasaki, Fanuc)

dziesiętnych części milimetra, co ma ogromne znaczenie przy wykonywaniu połączeń spawanych części cienkościennych. Rozpoznawanie nawet skomplikowanych przestrzennie obiektów może w niektórych przypadkach wyeliminować konieczność stosowania precyzyjnych układów pozycjonowania części spawanych. Odpowiednie zastosowanie czujnika zmniejsza czas cyklu produkcyjnego w porównaniu z korektą dotykową - o ile była możliwa, oraz znacząco poprawia jakość i powtarzalność procesu.

Wadą metody są znaczne wymiary głowic pomiarowych, powodujący wyraźne utrudnienia w operowaniu narzędziem (rys. 4) oraz bardzo wysoka cena, czasem przewyższająca koszt samego robota spawalniczego.

Pomimo ograniczeń, laserowe czujniki triangulacyjne stanowią nie tylko alternatywę dla systemów wbudowanych, znacznie wykraczając poza ich ograniczenia, ale także rozwiązanie dla wielu złożonych, często nietypowych zagadnień. Skanowanie przeważnie ma charakter ciągły, uwzględniający przebieg całej spoiny (rowka), bez istotnych ograniczeń co do grubości spawanych elementów i szerokości szczeliny. Podobnie jednak jak w przypadku najprostszej detekcji dotykowej, pomiar następuje przed spawaniem nowego zespołu, wydłużając czas jego wykonania, a także nie uwzględnia ewentualnych deformacji przebiegu złącza podczas procesu.

\section{Nowe rozwiązanie}

Rosnące zainteresowanie spawaniem zrobotyzowanym zespołów o obniżonej dokładności lub niedokładnym pozycjonowaniu skłoniło do opracowania autorskiego, innowacyjnego systemu skanującego z laserowym czujnikiem triangulacyjnym. Podjęte działania realizowane są $\mathrm{w}$ ramach projektu celowego FSNT-NOT nr ROW-III-141/2010 (ZAP Robotyka, Zakład Inżynierii Spajania Politechniki Warszawskiej), a ich bezpośrednim celem jest opracowanie oraz wdrożenie do produkcji uniwersalnego systemu laserowego 3D do śledzenia obiektów w zrobotyzowanych procesach spawalniczych. Dotychczas wdrażane stanowiska zrobotyzowane, pomimo bardzo dobrych parametrów technicznych, budowane były zgodnie z klasyczną koncepcję sterowania programowego (bez sensorów) lub z wykorzystaniem systemów wbudowanych, głównie opartych na detekcji dotykowej. Zastosowanie sensorów laserowych pochodzących od innych producentów, głównie z importu, z uwagi na bardzo wysoką cenę oraz często ścisłe dopasowanie do określonego typu robotów, nie było uzasadnione ekonomicznie lub wręcz niemożliwe.

Do najważniejszych cech nowo opracowywanego systemu laserowego zaliczyć należy:

- uniwersalność zamocowania do ramienia robota, zarówno bez, jak i z typowym złączem antykolizyjnym, także w przypadku tzw. pustego przegubu (HW),

- konstrukcję i montaż czujnika w jak najmniejszym stopniu ograniczającą swobodę manewrowania i dostęp uchwytu elektrodowego do miejsc spawania,

- uniwersalność systemu sterowania, umożliwiającą współpracę $z$ wieloma typami robotów,

- automatyczną przesłonę, mechanicznie separującą czujnik podczas spawania.

Wiele uwagi wymaga dobór sensora zapewniającego odpowiednie parametry użytkowe, takie jak zakres roboczy (odległość od obiektu, szerokość skanowania), czułość i rozdzielczość pomiarowa, odporność na rodzaj skanowanego materiału i stan jego powierzchni. Możliwa będzie detekcja szczelin od $0,1 \mathrm{~mm}$ oraz rozpoznawanie różnych profili, $w$ tym:

- rowków o ścianach równoległych i skośnych w stosunku do osi głowicy skanującej,

- naroży wewnętrznych (złącza ze spoinami pachwinowymi) i zewnętrznych (złącza narożne),

- uskoków w przypadku złączy zakładkowych lub spawania elementów o różnych grubościach,

- szczelin o nieregularnych kształtach,

- wypukłości, np. będących wynikiem wcześniejszego wykonania warstw lub ściegów w spoinach wielowarstwowych lub wielościegowych,

- innych, powstałych w pozostałych procesach, jak napawanie, montaż, obsługa, kontrola itp. 


\section{Podsumowanie}

Opracowano wiele programowych i sprzętowych metod korekcyjnych umożliwiających zrobotyzowane spawanie części o obniżonej dokładności ich przygotowania lub niedokładnie pozycjonowanych. W zestawieniu celowo pominięto bardziej zaawansowane rozwiązania, np. oparte na analizie obrazu czy skanowaniu laserowym bezpośrednio podczas spawania, głównie z powodu bardzo wysokich kosztów i ograniczonego zastosowania.

Pomimo wyraźnych ograniczeń funkcjonalnych systemów prostych - wbudowanych, należy pamiętać o ich zaletach. W sprzyjających okolicznościach mogą być zastosowane łącznie: po wstępnym rozpoznaniu położenia części metodą detekcji dotykowej może następować spawanie z ciągłą korektą rowka opartą na pomiarze parametrów łuku spawalniczego.

Laserowe czujniki triangulacyjne są obecnie szczególne wartym uwagi uzupełnieniem systemów wbudowanych, gdyż skutecznie łączą wysoką funkcjonalność i uniwersalność z malejącą ceną wdrożenia, dzięki nowym opracowaniom i rosnącej konkurencyjności.

\section{Literatura}

[1] Grohs K.: Roboty spawalnicze Fanuc - Wysoka funkcjonalność i łatwa obsługa. Spajanie Materiałów Konstrukcyjnych 2/2009.

[2] Jones C., Degórski P.: System pomiarowy scanCONTROL. Elektro Info 11/2006.

[3] Kruczyński M.: Roboty spawające Kawasaki: Funkcja Touch Sensing. Biuletyn Automatyki, ASTOR 3/2009.

[4] Lewandowski W.: Robotyzacja spawania - Aktualny kierunek. Spajanie Materiałów Konstrukcyjnych 3-4/2010.

[5] Materiały firmowe Kawasaki, Fanuc, Kuka, ABB.

[6] Petz M.: Współczesne zrobotyzowane spawanie. Przegląd Spawalnictwa 11/2009.

[7] Roboty Kawasaki na targach ExpoWELDING 2010. Biuletyn Automatyki, ASTOR, 4/2010.

\section{W następnym numerze}

\section{Benedykt Ślązak}

Analiza wartości chwilowych parametrów napięciowo-prądowych w ocenie stabilności procesu spawania elektrodą otuloną

\section{Marek Banasik, Sebastian Stano}

Lasery dyskowe - źródło ciepła dla procesów spawalniczych

\section{Izabela Kalemba, Stanisław Dymek}

Mikrostruktura i właściwości połączeń stopów aluminium wykonanych metodą zgrzewania tarciowego z mieszaniem materiału zgrzeiny

\section{Sławomir Krajewski, Jerzy Nowacki}

Mikrostruktura i właściwości stali o wysokiej wytrzymałości AHSS

\section{Łukasz Blacha, Aleksander Karolczuk}

Porównanie energetycznego modelu wyznaczania trwałości zmęczeniowej złączy spawanych do zaleceń międzynarodowych

\section{Jerzy Dobosiewicz, Wojciech Brunné \\ Przyczyny nieszczelności rurociągu wody amoniakalnej w obszarze połączeń spawanych}

\section{Lechosław Tuz, Paweł Kołodziejczak, Andrzej Kolasa}

Struktura złączy doczołowych odlewniczych stopów magnezu 